\title{
METODOLOGÍA IDENTIFICATIVA EN LOS DESASTRES DE MASAS
}

\author{
METHODOLOGY IDENTIFICATION IN MASS DISASTERS
}

\author{
OMAR Ampudia García ${ }^{1}$ \\ Universidad Complutense de Madrid, España \\ (RECIBIDO, 05/07/2012, ACEPTADO 30/11/2012)
}

\begin{abstract}
RESUMEN
Las grandes catástrofes en el Perú adolecen de un plan de tratamiento y adaptación a la realidad actual. Eran poco frecuentes y se limitaban a los desastres naturales como los grandes sismos, inundaciones, lluvias torrenciales, volcanes en erupción, etcétera. Al principio estos desastres se circunscribían a ciertas áreas geográficas en general, pero con el avance de la ciencia y la tecnología se han disparado de manera alarmante como los choques de ferrocarriles, accidentes aéreos, choques de autos que van a alta velocidad, y si a ello le sumamos los atentados de grupos fundamentalistas con coches bomba o lo de las Torres Gemelas. Estos hechos tienen un común denominador un elevado índice de siniestralidad y cuantiosas pérdidas materiales para un país.
\end{abstract}

Con la finalidad de dar una respuesta eficaz y planificada ante los desastres de masas es que se analiza las diferentes metodologías de actuación del protocolo de la Interpol, el Ministerio de Justicia de los Estados Unidos y el BOE Español.

Palabras clave: catástrofes, protocolos, identificación de víctimas de desastres y equipo multidisciplinar.

\begin{abstract}
Major disastersin Perulack froma treatment planandadaptto the current reality. Were rareand limited tonatural disasters such asmajor earthquakes, floods, torrentialrains, erupting volcanoes, and so on.At firstthese disasterswere limited tocertain geographic areasingeneral,but with the advancementof scienceand technologythese eventshave soaredalarminglyasrailcrashes, plane crashes, car crashesgoingat high speed,andifwe addthe attacksby fundamentalist groupswithcar bombsorthe Twin Towers. These factshave a common denominator, a highaccident rateandmaterial lossesfor a country. In order toprovide an effective responseto disastersand plannedmassis that itanalyzes theperformance ofdifferentmethodologiesInterpolprotocol, the Ministryof Justiceof the UnitedStates andtheSpanishBOE.
\end{abstract}

Keywords: Catástrophes, Protocols, mass disaster victims identification and multidisciplinar team

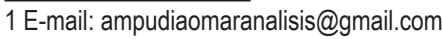




\section{INTRODUCCIÓN}

La cada vez más evidente automatización del entorno individual y del propio individuo es un potencial riesgo para la adquisición de un mayor extensión y gravedad en los desastres, y los consecuentes aumentos de la morbimortalidad; y si ello se adscribe a grupos o masas de gran contenido gregario, la mayor probabilidad de adquirir un desastre de grandes masas es marcadamente previsible.

Si a este entorno, le agregamos los eventos terráqueos y marítimos resultantes el cambio climático, la eventualidad de que se produzca una mayor gravedad en las catástrofes es probable.

Después del año 1950, los desastres en masas se hicieron más frecuentes por el avance de la tecnología y de la ciencia, por ello los accidentes aéreos, marítimos, ferroviarios, automovilísticos y otros, hoy son más frecuentes. Asimismo, las mega construcciones, como puentes, rascacielos, grandes centros comerciales, estadios, etc., donde trabajan, conviven y comparten tiempo libre grandes masas de personas, hacen que la probabilidad de mortalidad por siniestros aumente.

Por otra parte, los grandes seísmos, tsunamis y ciclones traen como consecuencia desastres de masas, lo que conlleva no solo la pérdida de vidas humanas sino también del medio ambiente, como ocurrió en Japón, en la central nuclear de Fukushima.

También tenemos que tener en cuenta que después de la década de los noventa, entró en escena un nuevo tipo de desastres en masas, no producido por la naturaleza o el avance tecnológico sino por el hombre, que es el terrorismo, como sucedió el 11-S con las Torres Gemelas en Estados Unidos, o el 11-M en España, solo para citar dos de los más importantes. No podemos tampoco dejar de lado los crímenes de lesa humanidad como los ocurridos en Kosovo, Ruanda, entre otros, que tuvieron un saldo de miles de personas fallecidas.

Por todo lo anteriormente expuesto, se hace necesaria una metodología de actuación multidisciplinaria en la investigación de desastres en masas.

El Real Colegio de Patólogos de Londres define desastre de masas como: incidente con múltiples fallecimientos, de tal magnitud que requiere disposiciones especiales para ser resuelto.

También se utiliza el término "Grandes Catástrofes". La palabra catástrofe proviene del griego Katastrepho, destruir. Según el diccionario de María Moliner y Larousse define catástrofe como "un suceso en que hay mucho daño y destrucción”.

Luego, grandes catástrofes significa eventos en los que se produce un gran daño y destrucción. Por tanto, aunque en algún caso se ha hecho una separación semántica entre desastres de masas y grandes catástrofes, en ambas referencias encontramos un común denominador que es la alta tasa de destrucción y siniestralidad.

En estos sucesos existe un número elevado de fallecidos los cuales generalmente presentan graves daños en el cuerpo humano de los cadáveres lo que dificulta la identificación; en estos casos se hace complejo por la violencia de los accidentes. 
Queremos puntualizar que, como señalamos al inicio, la mayor automatización de la población, en particular de aquella económicamente activa, se expresa en mayor ansiedad y problemas emocionales agudos; lo cual empeora cualquier raciocinio mental para la colaboración vital en presencia de una catástrofe $(1,2,3)$.

$\mathrm{Al}$ respecto, es de resaltar que, de acuerdo a la realidad actual, hoy más que nunca, la rapidez con la cual se pueden producir los accidentes tecnológicos, se ve empañada por la excesiva confianza y generalización que el hombre vuelca sobre la seguridad y la "perfección de los equipos automatizados", subestimando al mismo tiempo, la capacidad máxima de rendimiento profesional del componente humano. Por ello, es necesario revalorar en su real dimensión el gran potencial humano de trabajo en equipo, y la preservación y mantenimiento de su alta capacidad resolutiva, por encima de la máquina.

También, y desde un punto de vista histórico, examinando las catástrofes ocurridas vemos por continentes, que es en Europa en donde las catástrofes tecnológicas y causadas por el hombre alcanzan su mayor frecuencia; seguidas por el continente americano, con gran predominio de las catástrofes naturales; posteriormente, vienen los desastres naturales y climatológicos ocurridos en Asia, Oceanía y África; cobrando relevancia los desastres climatológicos en Asia, agravados letalmente por la elevada densidad poblacional (5).

Las grandes catástrofes y desastres en masas que dependen del hombre (y pueden ser prevenibles) se incrementan diariamente, en particular por el masivo empleo de altas tecnologías de elevado riesgo (en el primer mundo); y por la creciente densidad poblacional, sumada a las deficientes infraestructuras (en el tercer mundo) (5).

El estrés es una reacción normal frente a una situación anormal; pero su prevención, preparación y reconocimiento es subestimado con mucha frecuencia, en el personal operático de rescate.

Todo aquel que interviene en una catástrofe sufrirá un cierto grado de estrés, pero, actualmente, su tolerancia puede evolucionar a un trastorno patológico con conscuencias físicas y psíquicas potencialmente graves, dañando agudamente la salud mental del personal.

El mayor riesgo aparece cuando hay que hacer frente a las circunstancias abrumadoras que son inherentes a las catástrofes. Hacerse cargo de los fallecidos, supervivientes y familiares contribuye a causar presiones inusitadas y, a menudo, inesperada sobre el individuo que ha de actuar en respuesta al accidente.

Se recomienda que los planes de emergencia incluyan previsiones para contrarestar los efectos del desastre sobre el personal (Guía de Identificación de Víctimas de Catástrofes. Organización Iternacional de Policía Criminal. INTERPOL 1997).

En referencia a los diferentes profesionales que integran los equipos de identificación de víctimas, debemos resaltar el papel trascendental del antropólogo forense; el cual jugó un rol crucial en Perú en la identificación de víctimas desaparecidas, con los sucesos luctuosos del grupo subversivo fundamentalista Sendero Luminoso, 
causando casi 70 mil muertos. (Informe del Grupo de Análisis de Datos sobre Derechos Humanos de la American Association for the Advancement of Science para la Comisión de la Verdad y Reconciliación, 2002).

En este respecto, el citado autor refiere además que los antropólogos forenses juegan un papel fundamental en los incidentes de desastres masivos. La antropología forense es determinante en la precisión de la identificación humana, de acuerdo a Ubelaker (2007). (36).

\section{JUSTIFICACIÓN}

Las catástrofes de masas y las consecuentes víctimas desaparecidas han crecido exponencialmente (4), dando un giro espectacular a partir del fatídico 11 de Septiembre de $2001(5,6)$ :

1. De un lado, la inimaginable preparación de los equipos de rápida respuesta o de Salvamento Inicial, ante la magnitud e impredictibilidad de un desastre.

2. De otro lado, la amplia y decisiva cobertura de los exámenes de ADN; los cuales cobraron una importancia jamás vista anteriormente, dada la masiva cantidad de cuerpos incinerados por temperaturas no expuestas, previamente (con algunas excepciones).

3. Los exámenes forenses de identificación, como huellas dactilares, exámenes radiográficos seriados, y odontogramas, jugaban un papel primordial ante la ausencia de un reconocimiento posible del cadáver, siendo la obtención y estudio comparativo del ADN, un examen prescindible siempre y cuando los restos pudieran ser identificados con los exámenes mencionados. Ello cambió radicalmente desde 2001 (6), cuando, coincidentemente, la frecuencia de los desastres de aviación, por ejemplo, cobraron mayor incidencia, y generaron mayor número de víctimas carbonizadas o seccionadas; haciendo al ADN la prueba comparativa eje de identificación forense (con obtención concomitante del ADN mitocondrial).

4. Uno de los factores pronósticos de mayor importancia que afecta el número de víctimas fatales final (luego del accidente) es el intervalo de tiempo transcurrido desde la exposición a la catástrofe en el escenario hasta el tratamiento definitivo: se ha demostrado repetidamente una correlación directa entre este tiempo transcurrido, y la mortalidad total. Por tanto, para lograr los mejores pronósticos en la eficiencia final, es perentorio e imprescindible tener una rápida, coordinada y decidida respuesta, entre el equipo de respuesta inicial (primeros respondedores) y el equipo proveedor de cuidados definitivos.

5. Todavía, el mayor cambio necesario que debe operarse en España es el establecimiento de un adecuado consenso y coordinación entre los equipos iniciales de rescate e identificación (7), estableciendo un mando único de comunicaciones; otro de identificación de víctimas, y finalmente un directorde operaciones de rescate; y todos ellos respondiendo a un director examinador jefe.

6. Los diferentes estamentos institucionales comprometidos en la respuesta a una catástrofe normalmente no tienen comunicaciones fluidas, ni mucho menos trabajan 
al unísono: todo esto hace necesario crear cambios en la comunicación, coordinación, y particularmente en las líneas de autoridad, tanto para el equipo de salvamento y primera respuesta, como al equipo receptor de rescate.

7. Si no se destierran ineficaces direcciones, cargos burocráticos y de poco claras decisiones rápidas; cualquier desastre podrá originar una respuesta caótica $(8,9,10,11)$.

8. En España, como país del Primer Mundo, no existe un plan efectivo y mucho menos eficaz de acciones informativas comunicativas y preventivas. Es decir, sin una adecuada información (por ejemplo de la extensión/gravedad objetiva del suceso), no existirá una adecuada y efectiva comunicación bidireccional entre los miembros del equipo rápido de respuesta; y sin una comunicación efectiva y eficaz (retroalimentación emisor-receptor-emisor), no habrá la debida prevención, la cual es el primer brazo de la actividad operativa de salvamento de catástrofes.

9. La evidente (y muchas veces ocultada o sobreseída) carencia de una óptima coordinación, se agrava por la falta rigurosa de un plan de salvamento adaptado a los grandes cambios actuales de masificación, climatológicos, de riesgos generales y coyunturales, todos los cuales aumentan potencialmente la extensión y gravedad de cualquier catástrofe actual, en relación con aquellas que ocurrieron lustros o décadas previas.

10. Es urgente formar un riguroso plan de ejecución de acciones para la implementación de un programa de desastres, y muy en particular, la puesta en marcha de la ciencia emergente de la desastrología; es decir, un plan, de acciones de medicina de desastres (9); y ello cobra mayor relevancia ante la ausencia de un protocolo de tiraje en el rescate de víctimas heridas; un plan que debe tener el menor tiempo de ejecución; con la máxima preparación y coordinación previa.

Una "adaptación práctica, efectiva y eficaz" es lo que requiere urgentemente el plan de actuación ante los desastres en masas, frente a la coyuntura actual, tanto desde el punto de vista de las catástrofes naturales debido al cambio climático -más rápidas de lo esperado- como de la magnitud de las catástrofes terrestres y aéreas, todas ellas agravadas potencialmente por la velocidad excesiva a la cual ellas se desplazan "para confort de la sociedad actual", evidentemente tecnificada y completamente deshumanizada.

No existe una adaptación de los planes de acción para hacer frente a las grandes catástrofes en relación al frenetismo actual de vida, y al entorno ambiental "inflamatorio" y cambiante.

Debido al elevado número de desastres que se producen en la actualidad, se hace necesaria la revisión de las metodologías existentes y consensuar los criterios para la mejor actuación frente a los desastres en masas $(12,13,14,15)$.

La capacidad de respuesta de los diferentes países es distinta según sus políticas de coordinación, planificación y unificación de actitudes; a lo cual se suma, en particular la preparación y madurez de la población, capaz, por ejemplo, de no obstaculizar las labores de rescate y actuación de respuesta, lo cual redundará en la efectividad del trabajo de salvamento. 
Si es conocido que dentro de España, hay "muchas Españas”, donde las autonomías discrepan política, pero sobre todo técnicamente, en lo referente a asuntos públicos de interés sanitario o de protección civil, de las acciones unitarias de emergencia ante las grandes catástrofes; es perentorio y urgente unificar los planes de acción de emergencia y recuperación ante los desastres en masas y grandes catástrofes.

De esta manera, estableciendo una cadena de mando (un mando único para cada Autonomía Española, por lo menos...), se evitará y reducirá la gran desorganización que suele suceder ante un desastre de masas.

Además, creemos necesario crear un ente responsable de un equipo de respuesta operacional mortuoria ante desastres, semejante al DMORT del Protocolo del Ministerio de Justicia de los EEUU (2005). Este equipo inexistente en España es de suma importancia para la correcta actuación y adaptación de la morgue (o morgues móviles) para una idónea actuación forense final.

\section{Objetivos}

1. Estudiar desde el punto de vista histórico cómo han evolucionado los desastres en masas.

2. Revisar los protocolos del departamento de justicia de los Estados Unidos, Interpol y compararlos con el protocolo de España.

3. Establecer las recomendaciones para los protocolos de actuación ante desastres masivos.

\section{Materiales}

Se han utilizado los principales textos y protocolos que hacen referencia a la evolución de los desastres de masas.

\section{Material bibliográfico}

\section{Libros}

Entre ellos, y como más importantes se pueden citar a Palafox y col. (12); Anadón y col.(4), Moya y col.(3), y Noji y col. (10).

\section{Revistas}

Entre ellas, se pueden citar a Biesecker y col (6); Spiegel y col. (11); O`Neil y col (29); así como a Kanaan y col (8); Winskog y col. (13); Tena y col.(18); Lessig y col.(17); Edlich y col. (15); Peleg y col (22); Aylwin y col. (27) y Montelius y col.: todos ellos se cuentan entre los de mayor relevancia para la confección analítica de esta revisión.

\section{Protocolos}

- Protocolo diseñados en el Departamento de Justicia de los EE.UU(2005) 
- Protocolo de la INTERPOL (2007).

- Protocolo de España (2009).

\section{MÉTODO}

- Análisis de los textos indicados en materiales desde el punto de vista de su efectividad en la aplicación que se ha hecho en casos concretos, particularmente el Real Decreto del BOE del 16 de Enero de 2009 (32/2009).

- Análisis estadístico descriptivo de la aplicación de los protocolos señalados en material.

\section{RESULTADOS}

\section{Sobre la evolución histórica de los desastres de masas}

Los desastres naturales -terremotos, inundaciones, erupciones volcánicas, ciclones tropicales, incendios y muchos otros- han cobrado más de 3 millones de vidas durante los últimos 20 años, han afectado adversamente la vida de 800 millones de personas, y han causado más de 50.000 millones de dólares en daños a la propiedad. Tan solo en la última década, el número de refugiados y personas desplazadas por la guerra, la hambruna y la sequía en sus propios países se ha duplicado a cerca de 45 millones de personas en 1995. Casi diariamente ocurre un desastre en alguna parte del mundo. El incremento de la población en las planicies inundables a lo largo de áreas costeras vulnerables y cerca de fallas geológicas y la rápida industrialización de las economías en desarrollo, son factores que probablemente incrementarán la amenaza de los desastres naturales y tecnológicos (10).

Desde el primer desastre de masas en el Teatro de Viena (1881), hasta el año 2000; y desde el fatídico 11 de Septiembre en el World Trade Center, hasta la actualidad; el concepto básico y fundamental de previsión sin sub-estimación, se viene repitiendo, en la práctica operativa, de manera constante. Y, por más equipos sofisticados y elaborados y el mejor equipo de operaciones, si el hombre persiste en magnificar su capacidad resolutiva (y, sobre todo, la de los equipos tecnológicos) sin la amplia previsibilidad, ensayo y prevención máxima; los errores de confusión y caos, se repetirán por los siglos de los siglos (17).

Loa accidentes aéreos, al igual que en otros lugares, se han incrementado en gravedad y morbimortalidad, específicamente en España desde 1972, cuando un avión británico se estrelló en la zona de Montseny Catalán, hasta el accidente de Spanair en Barajas de 2008, en donde el número de fallecidos sobrepasó el millar (12).

En la década de los años 80, destaca el accidente aéreo acaecido en las proximidades de Mejorada del Campo, Madrid, el 27 de noviembre de 1983, en donde fallecieron 184 personas, identificándose solamente 160; de los cuales, 24 víctimas quedaron sin identificar; es menester destacar que más del $70 \%$ de los cadáveres fueron identificados por métodos odontológicos (12). 
Una de las primeras oportunidades en donde los análisis del ADN se emplearon exitosamente para identificar víctimas de desastres de masas ocurrió en 1990, en el accidente del Ferri de los países bajos (9).

La mayor identificación de restos humanos en conflictos violentos tuvo lugar en Argentina, Perú y en la antigua Yugoslavia, gracias a los análisis comparativos de las técnicas lofoscópica y biológicas en especial el ADN.

Entre las catástrofes con mayor mortalidad durante el periodo 90 al 2000, podemos citar el ciclón de Bangladesh, con 139 mil muertos; el terremoto sucedido en Turquía, en 1999, con 40 mil muertos; el huracán Mitch en Centroamérica, en 1998, con 20 mil víctimas; el terremoto de Tajakistan de 1998, con más de 9 mil muertos (5).

En la década de los años 90, uno de las catástrofes de mayor envergadura fue la del genocidio de Ruanda, con más de un millón de cadáveres, y en donde no existió prácticamente ningún proceso serio ni posible de identificación. Y en el año 2000, el ciclón de Eline en África del Sur, con más de 2 mil víctimas mortales (5).

La preparación constante ante un desastre de masas es hoy más que nunca, una prioridad nacional: incluso uno de los mejores países del orbe con una excelente e "inmejorable" preparación en rescates masivos de víctimas, como Japón (20), ha sufrido en Fukushima uno de sus mayores traspiés por una "sencilla" infravaloración de la catástrofe (los reactores nucleares no fueron capaces de tolerar un terremoto de severísima magnitud).

La tragedia del World Trade Center de EEUU del 11 de septiembre de 2001, enseñó una revolucionaria técnica de identificación con el empleo comparativo del ADN mitocondrial (6).

De la revisión de los protocolos mas importantes, hemos escogido los que pensamos son los de mayor relevancia en su efectividad, y para compararlos con el protocolo de España.

\section{Protocolo del Instituto Nacional de Justicia de los EEUU}

Este protocolo detalla concienzudamente, partiendo de un mando único del examinador médico, la coordinación operativa, tanto desde la esfera inicial de la información, a la que sigue la coordinación, planificación operativa directa y ejecución del plan forense de identificación.

El equipo de Operaciones de Salvamento y Rescate Inicial establece el inicio de un Sistema de Manejo de Incidentes / Sistema de Comando de Incidentes unificados.

En lo que refiere a los métodos identificativos, el ADN es perentorio en todos los casos de víctimas fatales; y es señalado como un componente esencial en el proceso de identificación.

Se hace especial hincapié en establecer unidades de trabajo móvil, para agilizar la calidad del operativo (14). 


\section{Protocolo de la INTERPOL}

Coincidiendo con el protocolo precedente, en donde se establece también un mando único, el cual recae en un comisario superior de la policía o un funcionario judicial superior, quien será el director jefe que a su vez tiene tres subdirectores, de comunicaciones, operaciones de rescate e identificación de victimas.

La Interpol establece una clara diferencia: los exámenes de ADN no son en primera instancia necesariamente imprescindibles; excepción hecha en los casos en los cuales los cuerpos sean completa y totalmente irreconocibles, y no se disponga de métodos dactilares y odontológicos posibles; y lo más importante: siempre el ADN comparativo (ante-mortem y post-mortem) debe interpretarse con base inicial en los exámenes forenses de identificación básica inicial. Naturalmente, previa identificación lofoscópica que es una prueba básica, constituyendo la primera línea de identificación.

Tanto el protocolo de la Interpol como el del Departamento de Justicia de EEUU, el director Jefe único tiene solo tres ejes direccionales: un director de comunicaciones, un director de identificación, y un director de operaciones de rescate.

El protocolo de la Interpol remarca enfáticamente en dos tópicos cruciales:

1) El de establecer un Centro Eficaz de Comunicaciones, el cual debe ser fluido, integral y práctico.

2) El de reconocer y tratar el estrés agudo en el personal; pero sobre todo el poder evitarlo mediante programas previos de ejercicio físico regular, una alimentación adecuada, y turnos de descanso apropiado; todo lo cual, al elevar la salud mental del individuo, redundará en una mejor performance y calidad del rendimiento final del Equipo en su totalidad $(10,23)$.

\section{Protocolo de España}

Recogido en el BOE- 2009, el protocolo último español tiene dos competencias paralelas: el Ministerio de Justicia y el Ministerio del Interior.

Este protocolo presenta 37 artículos, contenidos en 4 capítulos para la actuación de distintas instituciones que participan en la identificación de víctimas de desastres. En el capítulo 1 trata de las disposiciones generales; en el capítulo 2 versa sobre sus fases de actuación, distribuidas en 3 secciones primera, fase de actuación, segunda, fase de actuación preliminar, tercera, fase de tratamiento de cadáveres y restos humanos, y cuarta fase de obtención de datos ante-mórtem, y asistencia a familiares.

El capítulo 3 trata de la actuación coordinada de los laboratorios; mientras el capítulo 4 presenta la integración de datos.

El protocolo presenta además 7 anexos, en los cuales especifica diversos formularios, actas, así como normas para la recolección de muestras de ADN. 
A modo de resumen podemos consultar la Tabla 1.

\section{Estadísticas sobre Grandes Catástrofes}

Desde el punto estadístico se puede observar que desde el año 1960 al 1969, un aumento en todo tipo de catástrofes, siendo de notar que el mayor número corresponde a desplazados.

\section{Figura 1}

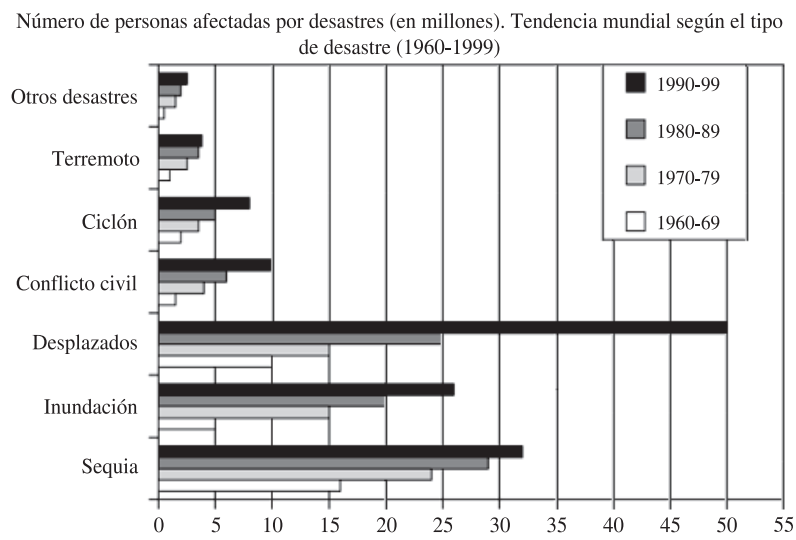

Fuente: Elaboración propia (Unidad de Investigación en Emergencia y Desastres. Departamento de Medicina. Universidad de Oviedo) a partir de datos de la $O \mathrm{CDE}^{10} \mathrm{y}$ del $\mathrm{CICR}^{1,2}$

Fuente: Unidad de Investigación en Emergencia y Desastres. Departamento de Medicina. Universidad de Oviedo.

(Extraído de: Arcos I y Col Rev Esp Salud Pública 2002; 76: 121-132).

Desde el punto de vista de la distribución por continentes, podemos observar que el que tiene un mayor coste por desastre es el continente europeo y el que menor el africano.

Ver figura 2

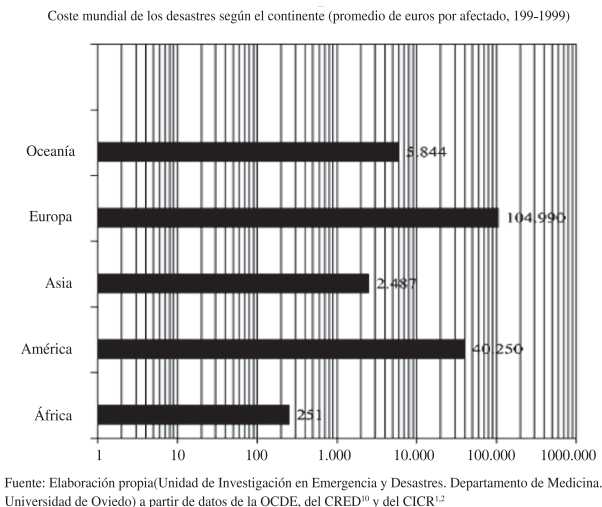

Fuente: Unidad de Investigación en Emergencia y Desastres. Departamento de Medicina. Universidad de Oviedo. (Extraído de: Arcos I y Col Rev Esp Salud Publica 2002; 76: 121-132). 
Desde el punto de vista estadístico, en la necro identificación de cadáveres calcinados, el método odontológico -en este estudio de 1983- demostró ser el más efectivo, en comparación a los métodos tradicionales, exceptuando al ADN que por ese entonces no se encontraba en uso. (Figura 3).

\section{Figura 3}

INVESTIGACIÓN DE CATASTROFES PORCENTAJES DE MÉTODOS: 27-11-83

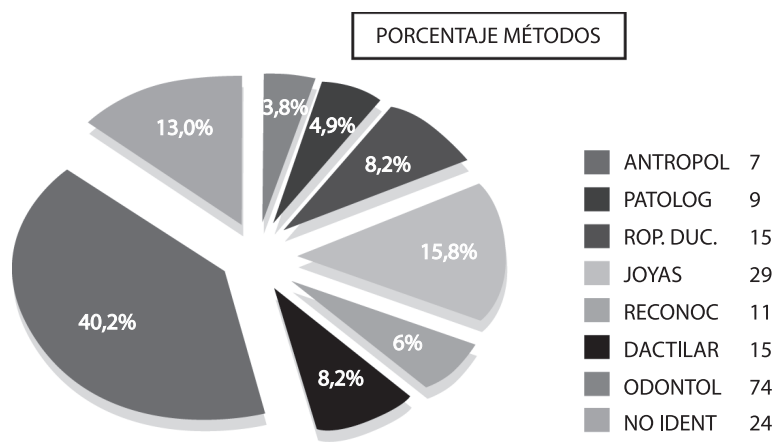

(Extraído de: López Palafox J. Desastres en Masa: actuación de grupos de investigación. Link: Importancia de los procedimientos odontológicos.

http://www.gacetadental.com/noticia/5625/ODONTOLOGíA-FORENSE/odontología-forense-grandes-catástrofes.htm

En estas figuras (a) y (b), se aprecia que el mayor porcentaje del tipo de desastres de fuego obedece a causas industriales, seguidos por los accidentes de tráfico (a); y el mayor porcentaje de fallecidos que responde, igualmente, al avance ciego de la tecnología (b).

\section{Figura 4}

614 AMERICAN JOURNAL OF EMERGENCY MEDICINE Volumen 14, Number 6 October 1996

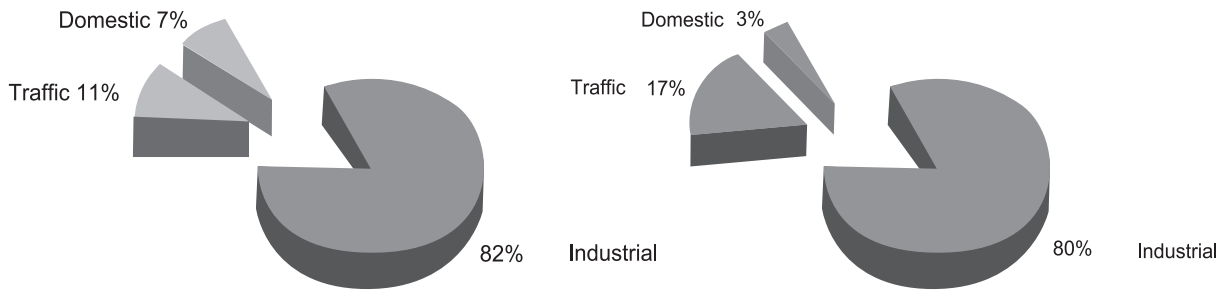

Fuente: Hadjiiski O. First Aid and Transportation of Burned Patients During Mass Disasters. Am J EmergencyMed 1996; 14(6): 613-614. 


\section{DISCUSIÓN}

Los desastres, con frecuencia, desbordan la capacidad de los sistemas locales que se encargan de atender a los fallecidos. Son entonces las comunidades y las organizaciones locales las que asumen la responsabilidad principal de la respuesta.

La falta de asistencia o de planificación especializada para las situaciones con víctimas en masa incrementa todavía más los problemas y, a menudo, ocasiona un manejo inadecuado de los cadáveres.

El trato que reciban las víctimas tiene un efecto profundo y duradero en la salud mental de los sobrevivientes y de las comunidades, que pueden tener graves implicaciones en el futuro. De igual forma, la correcta identificación de los muertos tiene importancia legal para los herederos y para las compañías de seguros, y pueden tener serias repercusiones en los familiares muchos años después del desastre

En el protocolo del BOE español se evidencia una clara diferencia entre las normativas teóricas, muchas veces, poco claras, y la puesta en práctica en el escenario de dichas y, muchas veces confusas normativas; ello puede ocurrir, y ocurre, en particular ante un desastre de magnitudes insospechadas.

En pleno siglo XXI, no puede concebirse un plan de lineamientos indefinidos, en cuanto, por ejemplo, al personal integrante de los equipos más importantes en una catástrofe: el equipo de salvamento y rescate inicial, de carácter preventivo y recuperativo (11); y el equipo post-mortem forense de rescate e identificación. Aparte de la dualidad en la jefatura de mando -dos ministerios a cargo de iniciar la información y coordinación- ralentizan en exceso el inicio del operativo. La direccionalidad rápida de la información. Coordinación, ejecución y actuación se contradice en lo referente a un mando único en el equipo de respuesta inicial.

Es mandatario en los protocolos de la Cruz Roja el dar exclusiva prioridad al rescate de los supervivientes y a la búsqueda y rescate de las víctimas desaparecidas, siempre antepuestas a la identificación forense.

En cuanto a las diferencias que cobran mayor relevancia entre los diferentes protocolos aquí señalados, se establece el establecimiento de un único equipo de mando operacional presente en el equipo de emergencias de rápida respuesta. Como ejemplo, citaremos los protocolos de la Cruz Roja Internacional.

De otro lado, en lo referente a la velocidad de respuesta (una hora) desde el rescate y soporte inmediato, hasta que las víctimas heridas llegan a un centro hospitalario (donde Alemania tiene el tiempo eficaz más corto), es imprescindible que exista, primero (y luego de manera concomitante) una coordinación eficaz y efectiva para un buen resultado final $(11,22)$.

En otras palabras, el conocimiento sobre la magnitud, gravedad y extensión del desastre: la información exacta y la coordinación planificada no pueden sacrificarse a costa de una velocidad mayor inefectiva, puesto que ello conllevará a un efecto deletéreo sobre la capacidad real de respuesta ante el desastre $(12,22,25)$. 
En el análisis del Real Decreto del BOE del 16 de enero de 2009 (32/2009), se menciona una triste realidad nacional: la inexistencia de un protocolo de actuación conjunta y coordinada del equipo de médicos (forenses) y de las fuerzas de seguridad del Estado (Cuerpos de Seguridad Estatal, y Cuerpo de Policía Autonómica).

En los casos de grandes catástrofes con un elevado número de víctimas, como es el caso de los accidentes de aeronavegación comercial, y, por supuesto, lo acontecido en el World Trade Center, el 11 de septiembre de 2001, en Nueva York; se ha mostrado especialmente útil, el campo de la odontología forense, en particular, el estudio de las mandíbulas (26). En el caso de situaciones límite, en las cuales existen explosiones extremadamente violentas, seguidas de incendios y derrumbamientos, donde las temperaturas alcanzan el orden de los 2000 grados centígrados, es prácticamente imposible la identificación de víctimas (26).

Agregaríamos aquí de forma asertiva la inoperancia completa y eficaz del equipo médico forense, en ausencia del médico de emergencias $(11,27)$, aquel preparado especialmente para salvar vidas en condiciones de extrema urgencia y emergencia, y cuya especialidad no existe en España.

$\mathrm{Al}$ respecto, indicaremos que, justamente por su carácter preventivo es requisito urgente establecer la existencia, en medicina de la especialidad de emergenciología $(11,27)$, en equivalencia al anestesiólogo, como sucede en Francia; o al profesional paramédico, en Reino Unido y EEUU - para su trabajo conjunto con el equipo de medicina forense (y todo el equipo de salvamento estatal).

De manera análoga, al arte clínico del rescate inicial, la odontología forense ha demostrado (al igual que la dactiloscopia), según un estudio hecho en Dinamarca en relación a las catástrofes aéreas, una muy alta efectividad en la identificación humana de restos incinerados y grandes quemados (28); pues son las piezas dentales los tejidos de mayor resistencia ante exposiciones prolongadas del fuego (ver adelante).

La capacidad del desarrollo en la reducción de riesgos en desastres; y, lo que es más práctico, su eficacia en la prevención y mitigación de un desastre mayor, todas ellas son los principales objetivos del programa de entrenamiento $(22,11$, $30,29)$ :estas acciones preventivas contribuirán a la mejora sustancial de la capacidad individual y especialización institucional. Todo ello en conjunto fomentará el desarrollo de estrategias de desarrollo local, las cuales, debidamente integradas, y coordinadas, reducirá el riesgo incrementado de desastres; factor decisivo y clave para los procesos de desarrollo sostenible de un país.

Cuando debemos implementar un plan riguroso de Medicina de Desastres, una ciencia emergente de carácter multidisciplinario, que debe formarse, implementarse y adaptarse a la complejidad de todos los desastres, con la finalidad de reducir la magnitud de daños humanos; con particular énfasis en las catástrofes telúricas (22).

Antes de implementar este plan, es requisito indispensable mantener los equipos institucionales (policías, médicos, bomberos, forenses, psicólogos...) con la misma y selecta plana de personal: inclusive ante la mejor planificación y diseño 
del mejor plan, la efectividad y eficacia será ostensiblemente reducida cuando existen continuos (y no comunicados) cambios en el personal (International strategyfordisaster reduction-United-Nations-2011http://www.unisdr.org/we/inform/ publications/18933)

A propósito, este protocolo de las Naciones Unidas -Estrategia Internacional para la Reducción de Desastres, 2011 (31) es el que otorga mayor énfasis en reconocer, afrontar y tratar el estrés agudo que aparecerá en el equipo de salvamento y rescate inicial, un estrés excesivo que sobrepasa la capacidad fisiológica del individuo.

Hace una década, los desastres en masa no acarreaban tantas consecuencias de orden psicológico agudo, que ponían en riesgo el mantenimiento del equilibrio de la salud mental. Sin embargo, en las circunstancias actuales, además de las comprensibles reacciones de estrés agudo en los supervivientes, este desborde en la tolerancia al estrés ocurre en el personal de rescate. Es el personal médico, en especial, y el de rescate, en general, el que es cada vez más proclive a presentar desórdenes de estrés post-traumático, tanto a corto como a largo plazo (22); históricamente, Katsouyanni refiere, desde 1986, un incremento substancial en los desórdenes cardiacos agudos (ref. 22).

Toda catástrofe, al ser un estrés agudo, origina, inmediatamente, y a largo plazo alteraciones de la bioquímica y del equilibrio celular y orgánico, aumentando los procesos inflamatorios ocultos en el organismo, (32), desde un infarto de miocardio, hasta una muerte súbita (22); ello quedó trágicamente patentado en las muertes posteriores a la catástrofe de Fukushima. $(20,21)$.

La prevención de crisis y la mitigación en la magnitud de los desastres debe ser parte integral en las estrategias de desarrollo humano, para el permanente avance, previsión, prevención, actuación y desempeño final (performance total) del equipo de desastres de masas; concomitantemente, deberá percibirse los errores de concepción, planificación y ejecución, todos ellos posibles y eventualmente corregibles rápidamente, pero solo cuando se enfocan desde una perspectiva: El rendimiento efectivo de un equipo global es mayor que la suma de sus partes.

Deberá quedar establecido que el potencial humano es y será siempre susceptible de alcanzar un mayor desarrollo dinámico y completo que el siempre sobreestimado potencial de la máquina sobre el conocimiento y el arte humano: el ejemplo más patente y relevante se observa en el desastre del reactor de Fukushima; el cual se hubiera podido prevenir si no se hubiera sobreestimado el umbral de tolerancia del reactor para tolerar seísmos de elevada magnitud.

Es muy importante puntualizar una vez más la crucial importancia de la prevención conjuntamente con el plan de acción: ello quiere decir que la prevención, sea como idea, sea como plan, sea como aplicación, no debe estar aislada del plan de acción de emergencias durante toda su ejecución (y durante la totalidad de su duración).

Por ejemplo, mientras los bomberos rescatan las víctimas mortales de un incendio; concomitantemente debe funcionar el plan preventivo para evitar la extensión del 
desastre a nivel humano y material: chorros de agua helada debidamente rápidos y simultáneos podrán evitar el recalentamiento de las zonas aledañas, evitando la extensión mayor del incendio.

Comprobamos que el método que más ha funcionado desde 2005 es el método del ADN mejorado, luego de su exhaustiva: 1) recolección, 2) depósito, 3) análisis (amplificado y diseñado / interpretado, 4) análisis comparativo, y 5) Coincidencias "matching".

De manera global, en situaciones en donde la identificación del cuerpo no es viable, dado que las estructuras dentales son los tejidos más durables del cuerpo, siendo capaces de soportar prolongadas y muy elevadas temperaturas (Hill, ForensicSciInt. 2011), la odontología forense ( Hill, 2011), y los análisis del DNA son los mejores métodos para la identificación de las víctimas mortales; en el caso más frecuente de la preservación del cadáver, las huellas digitales son el método más económico, en particular para las regiones más desfavorecidas económicamente del "Tercer Mundo".

La comunidad internacional desde hace tres décadas pretende responder rápidamente a las catástrofes naturales y a aquellas provocadas por el hombre; pero a pesar de los mayores avances en comunicaciones, tecnología; planificación y organización inter-institucional; subsisten muchas fallas simples en su concepción, pero, lamentablemente infravaloradas $(33,34)$, como es la tan frecuente confusión general, y las "sutiles" fallas en la comunicación, errores que inciden, particularmente en la información exacta, y en la eficiencia de las operaciones de recuperación e identificación de víctimas (34).

\section{CONCLUSIONES}

1. Las catástrofes de masas han aumentado exponencialmente de manera prácticamente paralela al incremento de la tecnología; y la sofisticación y la subestimación de la prevención han dado como saldo el aumento de la morbi-mortalidad por desastres masivos. Desde el desastre del teatro de Viena en 1881, hasta nuestros días se vienen produciendo más y peores catástrofes y la densidad poblacional creció de manera directamente proporcional con la tecnología y los desastre masivos; además, el número de catástrofes naturales se ha incrementado por los severos, (y desdeñados) efectos del cambio climático.

También, las grandes movilizaciones de personas y el uso de vuelos comerciales, así como de trenes de alta velocidad y otros medios de transporte han sido un caldo de cultivo de más desastres a nivel mundial. También lo sucedido en la central de Fukushima puso al descubierto magnas falencias en el sistema de desastres en masas a una potencia mundial como Japón.

Lo sucedido el 11 de setiembre del 2001 en las Torres Gemelas nos dio una lección al mundo civilizado que debemos tener un plan de respuesta eficaz ante desastres producidos incluso por grupos fundamentalistas. 
2. Los protocolos del Ministerio de Justicia de EEUU y el protocolo de la Interpol, comparados con el BOE de España, son de mayor definición; ellos tienen concretos sus lineamientos de prevención, coordinación, planificación y operatividad.

Si bien es cierto que, teóricamente, el BOE último rescata los puntos totales del plan forense de rescate e identificación; finalmente, vale decir, en la práctica, sus aseveraciones y recomendaciones se quedan algo indefinidas, y sujetas a confusión; el mejor ejemplo es la dualidad en la jefatura de mando que no existe en los protocolos señalados previamente.

3. Las recomendaciones planteadas y que pueden verse a continuación, se basan en la experiencia recogida en los protocolos examinados y en la bibliografía internacional al uso.

\section{Recomendaciones para mejorar los protocolos de actuación ante grandes catástrofes}

Del presente análisis y revisión, sugerimos las siguientes recomendaciones para la mejora en la eficiencia y eficacia en el actual protocolo español:

a. Existencia de un mando único, eliminando por completo la dualidad existente (14, $19,12,1,2,3,4,6,7,8,9,10,11)$.

b. Establecer de manera obligatoria la participación de las Comunidades Autónomas, y no de forma opcional, como se recoge del BOE actual.

c. Precisar las cadenas operativas subsiguientes de mando.

d. Debe existir un equipo profesional de expertos pre-establecidos, para la rapidez logística, operativa e identificadora.

e. En el equipo de salvamento, rescate inicial y rápida respuesta, debe incluirse la presencia de un médico emergencista; o en su defecto, anestesiólogo, para la realización eficaz y rápida del tratamiento de emergencia inicial.

f. Establecer una Jefatura única responsable de la respuesta forense, independiente de cualquier ministerio u otra entidad estatal burocrática

g. Establecer una efectiva operatividad de los equipos de Radio y su eficacia, dado que el sistema de telefonía móvil, se sobresatura y colapsa.

h. Priorizar la rapidez con calidad máxima en todo el proceso identificativo.

i. Es primordial personalizar los profesionales en las figuras del patólogo forense, el odontólogo forense y el antropólogo forense (16), tanto en el equipo de reconocimiento, identificación de víctimas, como en el levantamiento del cadáver, y para su necesario trabajo coordinado permanente. Estas intervenciones no se mencionan como tal, en el BOE actual. Es más, el Instituto de Gendarmería y Ciencias Forenses de Francia, recomienda que, idealmente, el equipo forense esté compuesto no solamente por un médico patólogo sino por dos odontólogos, un asistente de autopsias, y un número variable de técnicos policiales (16). 
j. El equipo forense post-mortem debe examinar, idealmente, un número de cuerpos humanos no mayor de ocho por día, dado el estrés excesivo y la menor pericia investigativa que ello supone (16).

k. Establecer de inmediato el método identificativo forense prioritario, y particular, para cada gravedad y tipología de las grandes catástrofes.

1. Establecer la independencia del equipo legal forense, y que no dependa de ninguna entidad ministerial, por la evidente ralentización, competencia y celo entre dichas entidades $(19,20)$.

m. Establecer un equipo de salvamento de rápida respuesta, un equipo de evacuación y recibo de víctimas; y un equipo de evaluación y coordinación forense (equivalente al DMORT).

n. Fomentar el entrenamiento regular frecuente (mínimo mensual) del o los equipos operacionales tanto el de salvamento y rápida respuesta como el equipo forense de recuperación.

o. Prevenir y controlar los problemas psicológicos frecuentes y el estrés intenso al que es sometido el equipo de rescate $(22,23)$, en particular el equipo de salvamento médico (22).

p. Preparar a la ciudadanía para que no obstaculice con su intervención, acción u omisión, en los desastres de gran envergadura; y por supuesto, esté óptimamente preparada para cualquier eventualidad.

q. Es imprescindible y urgente dotar al equipo de salvamento de rápida respuesta inicial, de un médico emergencista, a semejanza del médico anestesiólogo (Francia), o del profesional paramédico de excelencia (como en Reino Unido y EEUU)

r. En lo referente a los exámenes del ADN, es perentorio dirimir la responsabilidad de su realización en un solo organismo, llámese Policía Científica, Instituto Nacional de Toxicología; en comparación a lo existente en la actualidad en las comunidades autónomas, en donde trabajan con laboratorios privados.

s. Como máximo, en respuesta a una Jefatura única, tres estamentos (y solo tres) responderán a la catástrofe; y todas ellas de manera consensuada y coordinada (ver Tabla 1).

t. Desterrar, en lo humanamente posible, la tramitación cruzada (17), y la comunicación burocrática, muy presente en el protocolo del BOE (18).

u. La precisa recolección de los datos ante-mórtem es crucial e imprescindible para una efectiva identificación de víctimas de desastres (DVI); sin ella, no sería posible mantener la integridad y dignidad individual del fallecido (13).

v. Cada desastre tiene su propio escenario; y cada escenario define sus métodos propios de Identificación (9) siempre dentro de los marcos referenciales de los protocolos establecidos. 
Por ejemplo, en la gran catástrofe sucedida con las Torres Gemelas de EEUU, en 2001, un desastre de inimaginables proporciones, quedó patentizada la primordial actuación del antropólogo forense, al momento de recuperar, clasificar, reasociar, y ulteriormente, individualizar los restos humanos identificables (36). Sin embargo, sencillos errores de prevención, pudieron haberse claramente evitado; y reduciendo así la enorme magnitud de mortalidad (23).

\section{Tabla 1}

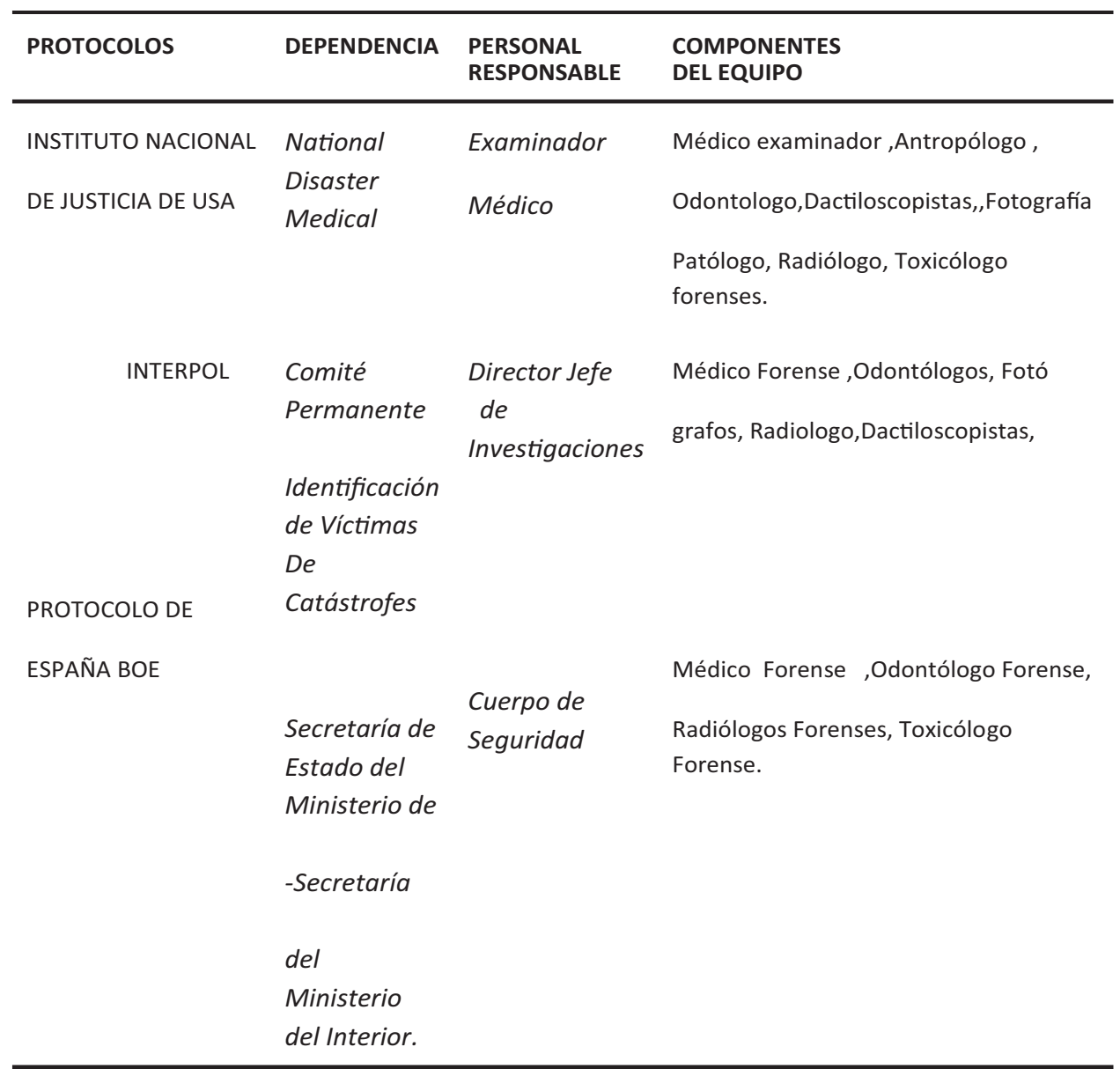

\section{REFERENCIAS BIBLIOGRÁFICAS}

Barrier G. Emergency medical services for treatment of mass casualties Crit Care Med. 1989 Oct; 17(10):1062-7.

Baker DJ, Telion C, Carli P.Multiple casualty incidents: the prehospital role of the anesthesiologist in Europe AnesthesiolClin. 2007 Mar; 25(1):179-88, 11.

Moya P, Roldán B, Sánchez J. Odontología Legal y Forense.Barcelona: Ed. Masson. 1994. 
Anadón M, Robledo M.Manual de Criminalística y Ciencias Forenses. Tébar Ed. Madrid, 2010 .

Arco González PI, Castro Delgado R, del Busto Prado F.Desastres y Salud Pública: un abordaje desde el marco teórico de la Epidemiología. Rev Esp Salud Pública 2002; 76: $121-132$.

Biesecker LG, Bayley-Wilson JE, Ballantyne J, Baum H, et al.DNA Identification After The 9 /11 World Trade Center Attack Science. 2005 Nov, 310(5751): 1122-1123.

Boletín Oficial del Estado: Real Decreto 32/2009 del 16 de Enero. Protocolo Nacional de actuación medico-forense y de la policía científica en sucesos con victimas múltiples BOE 32- 1. España. Enero 16, 2009.

KanaanA, Cea V, Huertas P. Mecanismos de Coordinación Asistenciales en un Plan de Emergencias ante Catástrofe. Rev Esp Med Legal, 2008, Oct, 13-21.

Montelius K, Lindblom B. DNA Analysis in the Disaster Victim Identification. ForensicSciPathol 2011; DOI 10.1007/s12024-011-9276-z.

Noji EK. Impacto de los Desastres en la Salud Pública. PAHO publicaciones, 2000.

Spiegel P, Burkle F, Dey C, Salama P. Developing public health indicators in complex emergency response.Prehospital and disaster medicine: the official journal of the national association of EMS Physicians and the worldassociation for emergency and disaster medicine in association with the acute care foundation.PrehospDisasterMed. 2001, 16(4):281-285.

Palafox JL, Prieto Solla L, García-Franco PL.Investigación de victimas de desastres. Madrid. Ed. Bellisco.2002.

Winskog C. DVI missions in the Carribean: the practical aspects of disaster victim identification. Forensic Sci Med Pathol 2011; DOI 10.1007/s12024-011-9273-2.

NIJ. National Institute of Justice. Mass Fatality Incidents: A Guide for Human Forensic Identification. U.S. Department of Justice Office of Justice Programs. 2005, June, NCJ 199758 .

Edlich RF, Wish JR, Britt LD, Long WB. An organized approach to trauma care: legacy of R Adams Cowley. J Long Term Eff Med Implants. 2004;14(6):481-511.

Schuliar Y, Knudsen PJ. Role of forensic pathologists in mass disaster ForensicSci Med Pathol. 2011 Dec 13.

Lessig R, Rothschild M.International Standards in Cases of Mass Disaster Victim Identification (DVI).Forensic Sci Med Pathol 2004; Published online August 2011.

Tena EA, PeraBajo FJ.Actuación Médico-Forense en el Accidente de Spanair en Barajas, el 20 de Agosto de 2008 Rev Esp Med Legal. 2009; 35(1): 12-18.

ICRC Comité Internacional de la Cruz Roja. Missing people, DNA analysis and identification of human remains: A Guide to Best Practice in Army Conflicts and Other Situations of Armed Violence Geneva: ICRC, 2005.

Tanigawa K, Tanaka K. Emergency medical service systems in Japan: past, present, and future Resuscitation. 2006 Jun;69(3):365-70. 
Tanigawa K, Hosoi Y, Hirohashi N, Iwasaki Y, Kamiya K. Loss of life after evacuation lessons learned from the Fukushima accident. Lancet, 2012 March; 379.

Peleg K, Reuveni H, Stein M Earthquake disasters--lessons to be learned Isr Med Assoc J. 2002 May;4(5):361-5.

StellmanJM, Smith RP, Katz CL, Sharma V, Charney DS, Herbert R, Moline J, Luft BJ, Markowitz S, UdasinI, Harrison D, Baron S, Landrigan PJ, Levin SM, Southwick S. Enduring mental health morbidity and social function impairment in world trade center rescue, recovery, and cleanup workers: the psychological dimension of an environmental health disaster Environ HealthPerspect. 2008 Sep;116(9):1248-53.

Shirm S, Liggin R, Dick R, Graham J.Prehospital preparednessfor pediatric mass-casualty events Pediatrics. 2007 Oct;120(4):e756-61.

Olympia RP, Wan E, Avner JR.The preparedness of schools to respond to emergencies in children: a national survey of school nurses Pediatrics. 2005 Dec;116(6):e738-45

Verdú Pascual F. Autopsia. En: Calabuig G. Medicina legal y Toxicología. $6^{\text {a }}$. Ed. Mason. Barcelona: 2004. Vol. 1 p.291-292.

Aylwin CJ, Koenig TC, Brennan NW et al. reduction in critical mortality in urban mass casualty incidents: Analysis of triage, surge, and resource use after the London bombings of July 7, 2005. Lancet 2006; 368:2219-2225.

Schou MP, KnudsenPJ. The Danish Disaster VictimIdentification effort in the Thai Tsunami: organisationand results.Forensic Sci Med Pathol.2011 Nov 24.

O'Neill PA. The ABC's of disaster response Scand J Surg. 2005; 94(4):259-66.

Mattox K. The World Trade Center Attack.Disaster preparedness: Health Care is ready, but is the bureaucracy? Crit Care. 2001 Dec;5(6):323-5.

United Nations Disaster Risk Reduction in the United Nations: 2011. roles, mandates and areas of work of key : United Nations Entities.International Strategy for Disaster Reduction.ISDR .Geneva, UNISDR- 21. 2009.

Campbell CM, Edwards RR Mind-body interactions in pain: the neurophysiology of anxious and catastrophic pain-related thoughts. Transl Res. 2009 Mar;153(3):97-101.

Noji EK.Public healthin the aftermath of disaster. BMJ 2005; 330: 1379-1381.

Sweet D. Interpol: DVI best-practice standarts, an overview. Forensic SciInt 2010; 201: $18-21$.

Hill AJ, Lain R, Hewson I.Preservation ofdental evidence following exposure to high temperatures. ForensicSciInt. 2011 Feb 25;205(1-3):40-3.

Ubelaker D. Enterramientos Humanos: Excavación, análisis e interpretación. Madrid: Ed. Munibe 24. 2007 